\title{
DISTRIBUIÇÃO TEMPORAL E PROBABILIDADE DE OCORRÊNCIA DE CHUVA NO MUNICÍPIO DE JUÍNA (MT)
}

\author{
BATISTÃO, Alan Carlos - alan_batistao_afl@hotmail.com \\ LAVEZO, André - a.lavezo@hotmail.com \\ PESSOA, Marcos José Gomes - marcos-af@hotmail.com \\ Mestrandos em Biodiversidade e Agroecossistemas Amazônicos. Universidade do estado de \\ Mato Grosso, Alta Floresta, MT, Brasil \\ DALLACORT, Rivanildo - rivanildo@unemat.br \\ Doutor - Prof. Da Universidade do Estado de Mato Grosso, Departamento de Agronomia, \\ Tangará da Serra, MT, Brasil \\ CARVALHO, Marco Antônio Camillo de \\ Doutor - Prof. Da Universidade do Estado de Mato Grosso, Departamento de Agronomia, Alta \\ Floresta, MT, Brasil
}

\begin{abstract}
RESUMO: A análise do comportamento das chuvas e a probabilidade de ocorrência podem detectar tendências ou alterações no clima e servir como alusão para atividades agropecuárias e humanas. Com isto o presente trabalho teve como objetivo determinar as variabilidades anual, mensal e decendial, quantificar o número de dias secos e chuvosos e definir diferentes níveis de probabilidade de ocorrência de chuvas no município de Juína - MT. Utilizou-se os dados pluviométricos disponibilizados pela Agência Nacional de Águas (ANA), do período compreendido em 1980 a 2011, desconsiderando os anos de 1982, 1990 e 1991 devido a falhas durante a coleta de dados, totalizando um histórico de 28 anos. Utilizou-se o programa computacional Microsoft Excel ${ }^{\odot} 2010$ para a tabulação dos dados realizou-se médias e desvio padrão anuais, mensais, decendiais e analisou-se a ocorrência de dias secos e chuvosos. Para determinação dos diferentes níveis de probabilidade de ocorrência de precipitação, realizaramse estudos probabilísticos utilizando o modelo de distribuição gama incompleta. Verificou-se com os resultados que a distribuição pluviométrica na região de Juína (MT) apresenta variabilidade temporal anual. A maior precipitação mensal ocorre em janeiro com 335,12 mm e a menor em julho com $1,88 \mathrm{~mm}$, definindo a região com duas estações, uma estação seca de maio a setembro e outra chuvosa de outubro a abril. Os meses de dezembro, janeiro, fevereiro e março apresentam $90 \%$ de probabilidade de ocorrência de pluviosidade superior a $160 \mathrm{~mm}$.
\end{abstract}

Palavras-chave: Precipitação, Variabilidade pluviométrica, Probabilidade, Distribuição Gama. TEMPORAL DISTRIBUTION AND LIKELIHOOD OF RAIN OCCURRENCE IN JUINA (MT)

ABSTRACT: Behavior analysis of rainfall and the probability of occurrence can detect trends or changes in climate and serve as reference for human and agricultural activities. With this, the present study aimed to determine the variability yearly, monthly and ten-day, quantify the number of dry and wet days and set different levels of probability of rain in the city of Juína MT. We used rainfall data provided by the National Water Agency (ANA), in the period from 1980 to 2011, excluding the years 1982, 1990 and 1991 due to a failure to collect data, totaling a record 28 years. We used the computer program Microsoft Excel ${ }^{\odot} 2010$ for tabulating the data held means and standard deviations annual, monthly, decennial and analyzed the occurrence of dry and wet days. To determine the different levels of probability of precipitation studies were performed using the probabilistic model of incomplete gamma distribution. It was found with the results that the rainfall distribution in the region of Juína (MT) presents annual temporal variability. The highest monthly rainfall occurs in January with $335.12 \mathrm{~mm}$ and the lowest in July with $1.88 \mathrm{~mm}$, defining the region with two seasons, a dry season from May to September and a rainy season from October to April. The months of December, January, February and March have a $90 \%$ probability of rainfall exceeding 160 $\mathrm{mm}$.

Key-Words: Precipitation, Rainfall variability, Probability. Gamma distribution. 


\section{INTRODUÇÃO}

O estudo temporal das distribuições de variáveis climáticas é necessário para compreender os fenômenos meteorológicos, determinando seus padrões de ocorrência e permitindo uma previsibilidade razoável do comportamento climático de uma região, o que é uma ferramenta de grande valor para o planejamento e gestão de inúmeras atividades agropecuárias e humanas (DOURADO NETO et al., 2005).

Segundo Silva et al. (2007) a precipitação pluvial é um dos elementos meteorológicos de grande importância, pois está diretamente relacionada aos mais diversos setores da sociedade, de forma que o regime pluviométrico afeta a economia, o meio ambiente e a sociedade, como um todo.

A importância de se estudar essa variável meteorológica é mostrar que se pode prevenir vários transtornos que a chuva possa causar (SOUZA et al., 2006), além de servir de orientação para a determinação do calendário agrícola pelos agricultores possibilitando também o planejamento e desenvolvimento das atividades agrícolas regionais que estão pautadas no comportamento da precipitação pluvial (MARTIN et al., 2008).

Juína é uma cidade localizada no noroeste do estado de Mato Grosso com aptidão agropecuária, segundo IBGE (2009) destaca-se a pecuária com 543.334 cabeças de bovinos e a produção agrícola com 3.240 toneladas de arroz e 2.625 toneladas de mandioca. De todos os segmentos da economia, a agricultura é o que apresenta maior dependência das variáveis climáticas, o que ocasiona oscilações de produção, ao longo dos anos (MARTINS et al., 2010).

O estado de Mato Grosso, como os demais estados brasileiros, apresenta peculiaridades físicas, como vegetação, relevo e solos, além do posicionamento geográfico, que influenciam diretamente na distribuição das chuvas (MANCUZZO et al., 2011).O estudo temporal das precipitações mensais, anuais, volume, os regimes sazonais e intensidade das precipitações tornam-se importante para conhecer o comportamento temporal nas microrregiões mato-grossenses que como mencionado por Mancuzzo et al. (2011) são eminentes.

Catalunha et al. (2002) relata que o uso de funções densidade de probabilidade está diretamente ligado à natureza dos dados a que ela se relaciona. Sendo possível estimar através de arquivos temporais de dados de precipitação cálculos de probabilidade de ocorrência de precipitações, ferramenta importante para o planejamento de operações agrícolas e humanas.

Thom (1958) determinou parâmetros para os cálculos de probabilidade de precipitação através da distribuição gama que estima através de cálculos estatísticos a probabilidade de ocorrência de chuvas, sendo a distribuição gama utilizada por diversos autores Silva (1983); Assad et al. (1993); Assis (1993); Ribeiro e Lunardi (1997); Botelho \& Morais (1999) e Soares (1999) apresentando veracidade nos resultados.

As previsões agrícolas constituem o meio mais importante de servir a agricultura. Grande parte das técnicas de previsão numérica baseada na agrometeorologia fundamenta-se na relação estatística entre as variáveis dependentes que deverão 
ser estimadas (produtividade, datas da floração e da maturação, etc.) e as variáveis agrometeorológicas independentes (precipitação, temperatura, etc.) ou, ainda, as variáveis reduzidas (índices de umidade do solo, influência da umidade atmosférica) (DALLACORT et al., 2006).

Este trabalho teve como objetivo determinar as variabilidades anual, mensal e decendial, quantificar o número de dias secos e chuvosos e definir diferentes níveis de probabilidade de ocorrência de chuvas utilizando o modelo probabilístico distribuição Gama Incompleta para os dados de precipitação pluviométrica no município de Juína - MT.

\section{MATERIAL E MÉTODOS}

Juína está localizada na Mesorregião Norte mato-grossense, a $740 \mathrm{~km}$ da capital Cuiabá. Faz parte da Grande Bacia do Amazonas, apresentando clima equatorial quente e úmido, precipitação anual de $2.250 \mathrm{~mm}$ e temperatura anual média de 24ㅇ, (FERREIRA, 2001).

O estudo baseou-se em uma série de dados diários de precipitação disponibilizados pelo Sistema de Informações Hidrológicas, versão Web 3.0 ${ }^{\complement} 2001$ da Agência Nacional de Águas (ANA) (HIDROWEB..., 2012), coletados na estação meteorológica Fontanilhas com código 01158001, situada no município de Juína sob as coordenadas geográficas $11^{\circ} 20^{\prime} 27^{\prime \prime} \mathrm{S}$ e $58^{\circ} 20^{\prime} 13^{\prime \prime} \mathrm{W}$ e altitude de $250 \mathrm{~m}$.

A precipitação foi coletada com auxílio de um pluviômetro tipo Ville de Paris, instalado sobre um suporte de 1,5 m de altura do solo, no período de 1980 a 2011. Porém, foram desconsiderados os anos de 1982, 1990 e 1991 devido à falhas durante a coleta de dados, analisando assim dados de 28 anos.

Os dados foram tabulados utilizando o programa computacional Microsoft Excel 2010. Foram realizadas médias e desvio padrão anual, mensal e decendial para discussão dos dados. Também foi realizada análise de ocorrência de dias secos e chuvosos, onde foram considerados secos, dias com a precipitação inferior a $1,0 \mathrm{~mm}$ e chuvosos quando ocorreu precipitação igual ou superior a 1,0 mm (FIETZ et al., 2011).

Para determinação dos diferentes níveis de probabilidade de ocorrência de precipitação, foram realizados estudos probabilísticos utilizando o modelo de distribuição gama incompleta, seguindo a metodologia de Thom, (1958). Onde a função densidade de probabilidade é dada pela seguinte equação:

$$
f(x)=\frac{1}{\beta^{a} \Gamma(a)} x^{a-1} e^{-x / \beta}
$$

em que $a$ é o parâmetro de forma (adimensional), $\beta$ o parâmetro de escala ( $\mathrm{mm}$ ), $e$ a base do logaritmo neperiano, $x$ o total de precipitação $(\mathrm{mm})$, e $\Gamma$ o símbolo da função Gama, definida conforme a equação que se segue:

$$
\Gamma(a+1)=\sqrt{2 \pi a} a^{a} e^{a}\left(1+\frac{1}{12 a}+\frac{1}{288 a^{2}}-\frac{139}{51840 a^{3}}\right)
$$


Um dos métodos usualmente utilizados para o cálculo da precipitação pluviométrica mensal e níveis de probabilidade de ocorrência de chuva mensal e anual é o método dos momentos, que consiste em igualar a média $(\bar{Y})$ e a variância $\left(S^{2}\right)$ da amostra à média e à variância da população, originando as seguintes equações (ASSIS et al. 1996):

$$
\mathrm{a}=\frac{\overline{\mathrm{Y}}^{2}}{\mathrm{~S}^{2}}
$$

$\beta=\frac{S^{2}}{\bar{Y}^{2}}$

em que $\bar{Y}=$ precipitação média do período $(\mathrm{mm})$ e $\mathrm{S}^{2}=$ variância $\left(\mathrm{mm}^{2}\right)$.

\section{RESULTADOS E DISCUSSÃO}

O comportamento anual da precipitação revelou grande variação na distribuição de chuvas durante o período analisado, com diferença de $1.144,7 \mathrm{~mm}$ em relação á maior e menor pluviosidade observada. O ano em que ocorreu menor precipitação foi 1.993, com $1.362,8 \mathrm{~mm}$ e o ano de 1.983 foi o que apresentou maior índice pluviométrico, com $2.507,5 \mathrm{~mm}$, A média anual para o período foi de $1.867,05 \mathrm{~mm}$, com desvio padrão de 251,14 mm (Figura 1).

Precipitação (mm) Média

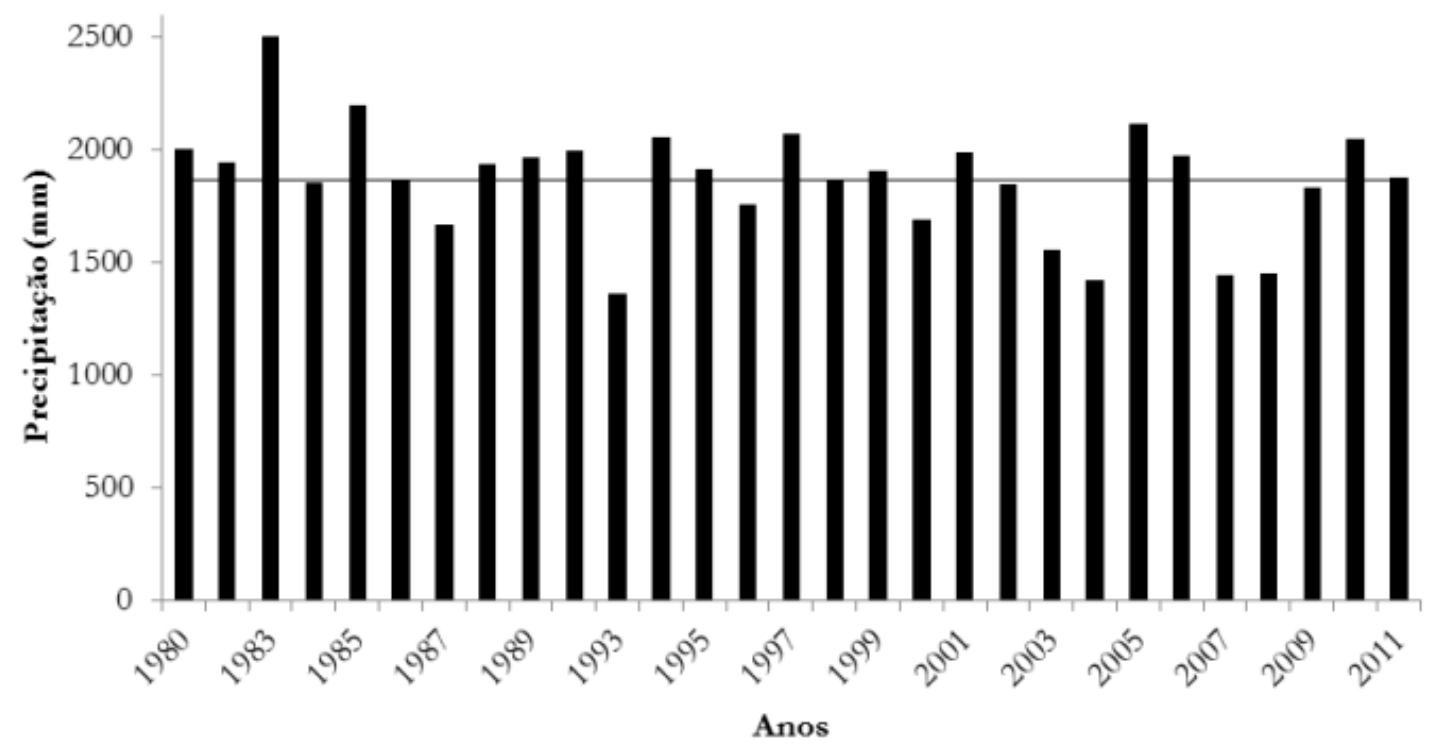

Figura 1. Precipitação anual e média no período de 1980 a 2011 para o município de Juína - MT.

Resultados semelhantes foram observados por Sousa et al. (2006), e Sousa et al. (2007) que analisaram a variabilidade pluviométrica em 43 municípios do extremo norte do estado de Mato Grosso no período de 1.990 a 2.001 , e verificaram que os municípios situados ao norte do estado apresentaram elevada variação pluviométrica de um ano para outro. Também, verificaram elevada pluviosidade nos municípios da 
região do extremo norte e noroeste do estado, com totais médios anuais de 2.100 a $2.500 \mathrm{~mm}$, valores estes superiores ao verificado para o município de Juína.

Rosa et al. (2007), estudando a distribuição e a variabilidade das chuvas anuais ocorrida na porção Centro-Oeste do estado de Mato Grosso entre os anos de 1985 a 1995, verificaram que a porção norte do estado de Mato Grosso apresenta os maiores índices de precipitação com valores superiores a $2.750 \mathrm{~mm}$, e diminuindo nas direções Leste, Oeste e Sul do Estado, resultando numa precipitação que se distribui de forma irregular. Ainda, os autores encontraram variações pluviométricas que oscilaram de 1.900 até $2.200 \mathrm{~mm}$, em estudos para os municípios de Brasnorte, Campos de Júlio, Juína, Nova Marilândia, Nova Mutum e Sapezal, localizados na porção centro-oeste do estado.

A partir da análise de dados da estação meteorológica de Juína, observa-se que apenas 3,57\% dos anos (1 ano) ultrapassaram $2.500 \mathrm{~mm}$ de precipitação, em $21,43 \%$ dos anos (6 anos) a pluviometria se manteve na faixa de 2.000 a 2.500 mm, em 64,28\% dos anos (18 anos) a precipitação permaneceu entre 1.500 e 2.000 $\mathrm{mm}$ e em $14,28 \%$ dos anos (4 anos) a precipitação foi inferior a $1.500 \mathrm{~mm}$, com $57,14 \%$ (16 anos) apresentando intensidade pluviométrica acima da média calculada para o período (Figura 1).

Corroborando com os resultados encontrados por Dallacort et al. (2011), que estudando a variabilidade pluviométrica anual da cidade de Tangará da Serra, em Mato Grosso no período de 1.970 a 2.007, verificou que em $24 \%$ dos anos, a precipitação anual ultrapassou $2.000 \mathrm{~mm}, 58 \%$ dos anos, a precipitação restringiuse na faixa de 1.500 e $2.000 \mathrm{~mm}$, e os restantes em $18 \%$ com a média estando abaixo de 1.500 .

A variação da distribuição pluvial anual pode estar correlacionada com a ocorrência dos fenômenos ambientais El niño e La niña que consistem durante algum período, secas mais acentuadas na região ou chuvas com maior intensidade, respectivamente.

Analisando a variação pluviométrica em relação à média anual para o período do estudo, observa-se que os anos de 1983, 1985, 1994, 1997, 2005 e 2010, apresentaram as maiores variações positivas em relação à média com 34,30\% $(640,54 \mathrm{~mm}), 17,81 \%(332,65 \mathrm{~mm}), 10,29 \%(192,15 \mathrm{~mm}), 11,10 \%(207,25 \mathrm{~mm})$, $13,16 \%(254,75 \mathrm{~mm})$ e $9,73 \%(181,75 \mathrm{~mm})$ respectivamente. Já os anos de 1993 , 2003, 2004, 2007 e 2008 foram os que apresentaram maiores variações negativas em relação à média, com respectivamente $27 \%(504,25 \mathrm{~mm}), 16,53 \%(308,65$ $\mathrm{mm}), 23,93 \%(446,85 \mathrm{~mm}), 22,88 \%(421,55 \mathrm{~mm})$ e $22,3 \%(416,35 \mathrm{~mm})$. Observase também, que $60 \%$ (17 anos) e 35,71\% (10 anos) dos anos apresentaram variação menor que $10 \%(186,7 \mathrm{~mm})$ e $5 \%(93,95 \mathrm{~mm})$ respectivamente para mais e para menos em relação a média (Figura 2 ).

Ao analisar as médias mensais de precipitação no período de 1980 a 2011, observou-se resultados semelhantes aos encontrados por Pizzato et al. (2012), Mancuzzo et al. (2011), Dallacort et al. (2011), Martins et al. (2010) e Rosa et al. (2007). No estudo, as maiores incidências de chuva ocorreram nos meses de dezembro a março, com médias superiores a $290 \mathrm{~mm}$, onde o mês de janeiro apresentou maior média de precipitação, com 335,11 mm. No período de maio a setembro, ocorreram baixos índices pluviométricos, com os meses de junho, julho e 
agosto caracterizando o período mais crítico, em relação ao regime pluviométrico da região, com médias mensais de $6,96 \mathrm{~mm}, 1,87 \mathrm{~mm}$ e $12,90 \mathrm{~mm}$ respectivamente (Figura 3).

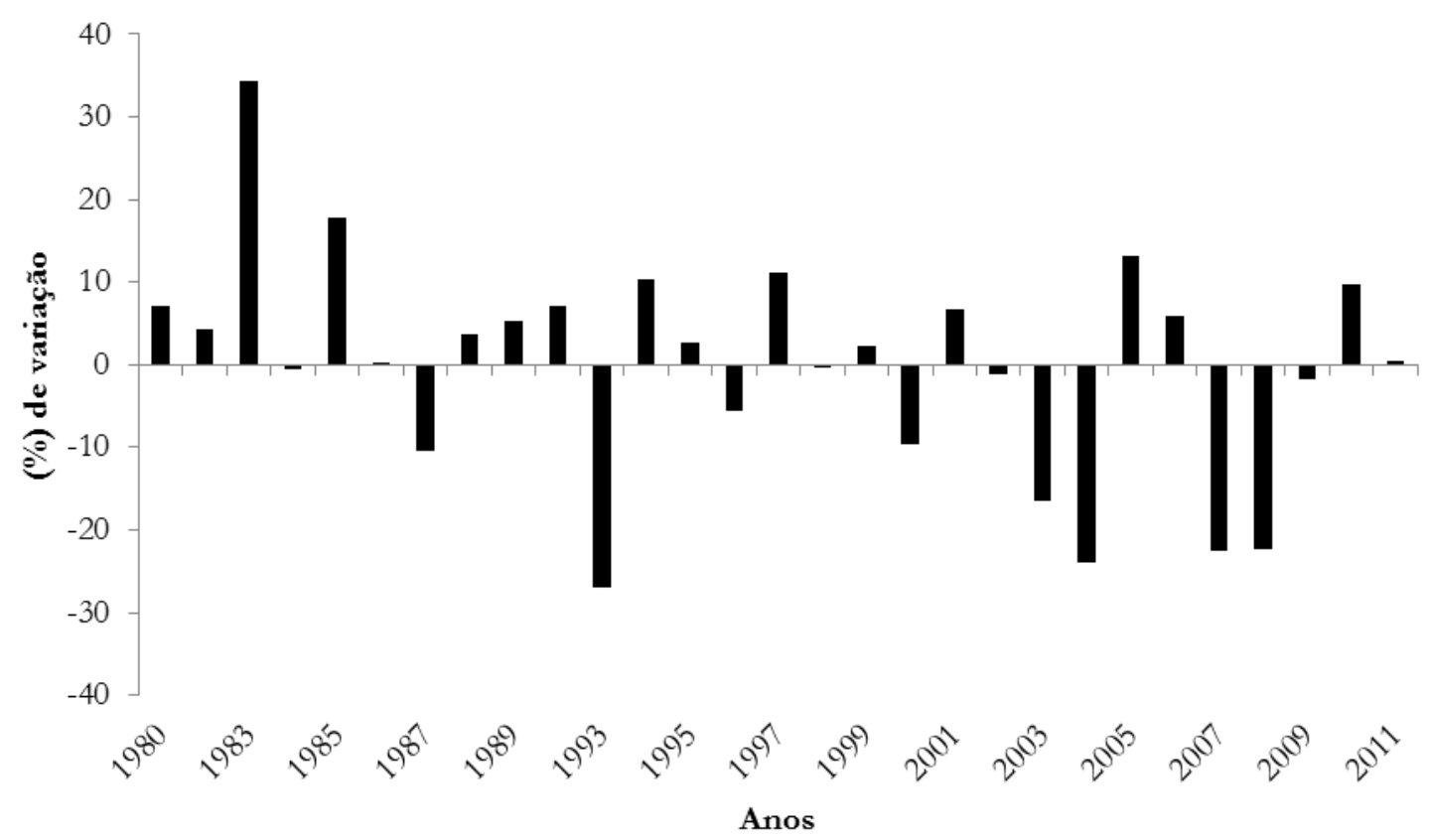

Figura 2. Variação temporal de precipitação em relação à média anual, em porcentagem (\%), para período de 1980 a 2011 no município de Juína - MT.

Dados similares foram observados por Marcuzzo et al. (2011) estudando a distribuição espaço-temporal e a sazonalidade das chuvas no estado de Mato Grosso, verificando que os maiores índices pluviais ocorreram nos meses de janeiro e fevereiro, com variação de 325 a 375 mm para o mês de janeiro e de 330 a $360 \mathrm{~mm}$ para o mês de fevereiro, ocorrendo no extremo norte e noroeste em áreas de bioma Amazônico.

Também, Rosa et al. (2007), concluíram que no inverno, em Mato Grosso, as chuvas são raras, com precipitações de quatro a cinco dias, concentrando totais entre 20 e $80 \mathrm{~mm}$.

Com os resultados, foi possível caracterizar duas estações bem definidas para a região de Juína, a estação chuvosa, compreendendo os meses de outubro a abril, e a estação seca, nos meses de maio a setembro, comportamento característico na região do cerrado (SOUZA, 1998; MANCUZZO et al., 2007) e do bioma amazônico (MANCUZZO et al., 2011), onde os meses de abril e outubro caracterizam-se como período de transição entre as estações. 


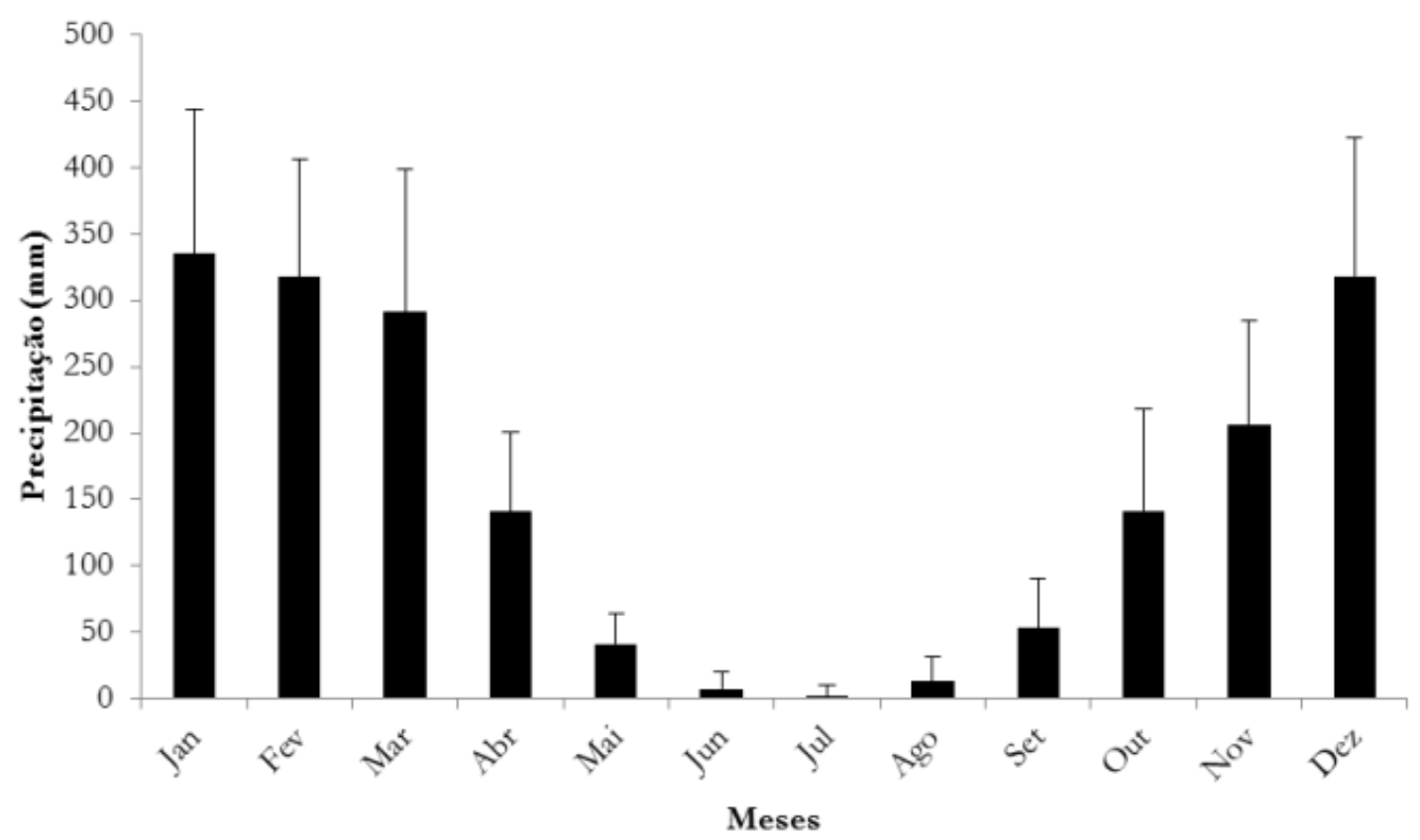

Figura 3. Médias mensais e desvio padrão da precipitação pluviométrica do município de Juína - MT, para o período de 1980 a 2011.

$\mathrm{Na}$ análise do comportamento da distribuição pluviométrica decendial (Figura 4) verifica-se que em 7 dos 36 decêndios, ou seja 19,44\%, a pluviosidade ultrapassou $100 \mathrm{~mm}$, sendo que o segundo decêndio foi o que apresentou maior precipitação com $132,17 \mathrm{~mm}$, seguido pelo quarto $(124,5 \mathrm{~mm})$ e pelo primeiro $(113,83 \mathrm{~mm})$, $30,55 \%$ dos decêndios (11 decêndios) permaneceram no intervalo de precipitação que variou de 50 a $100 \mathrm{~mm}$. Também se verificou que $11,1 \%$ dos decêndios ( 4 decêndios) ficaram na faixa pluviométrica de 25 a $50 \mathrm{~mm}$, e os $38,9 \%$ restantes (14 decêndios) apresentaram pluviosidade inferior a $25,0 \mathrm{~mm}$.

Ocorreu elevada precipitação nos primeiros cinco decêndios, com pluviosidade média de $115 \mathrm{~mm}$. A partir do décimo decêndio observa-se a diminuição nos índices pluviométricos, chegado a valores inferiores a $10 \mathrm{~mm}$ no décimo quarto decêndio, permanecendo nesta condição até o decêndio vinte e cinto. Neste período, a média decendial de precipitação foi inferior a $5 \mathrm{~mm}$. O decêndio que apresentou menor média foi o vigésimo, com valor de 0,05 $\mathrm{mm}$. 


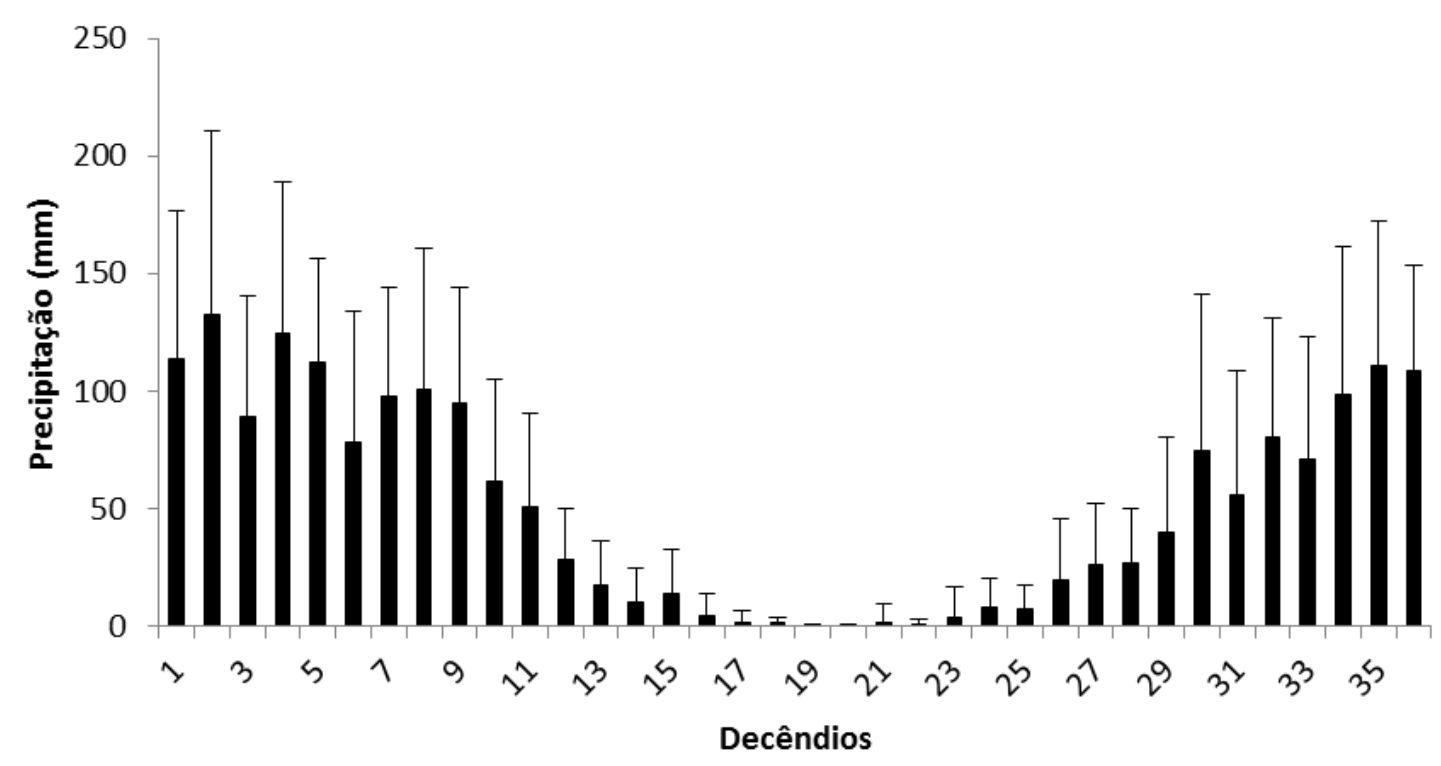

Figura 4. Médias pluviométricas decendiais do município de Juína - MT para o período de 1980 a 2011.

O número de dias secos e dias chuvosos na cidade de Juína - MT (Figura 5) indicam uma média geral de dias secos e chuvosos do período estudado de 252 e de 113 , respectivamente. Os anos mais secos foram 2005, 2006 e 2007 com 288, 285 e 297 dias sem precipitação. Já os anos mais chuvosos foram 1994 e 1995, com 147 e 149 de dias chuvosos e 219 e 216 dias secos respectivamente. Em 39,28\% dos anos (11 anos) o número de dias com precipitação foi superior à média de dias chuvosos, porém $50 \%$ (14 anos) dos anos, o número de dias sem precipitação foram superiores à média de dias secos.

Ao comparar os dados obtidos por Pizzato et al. (2012) com os do presente estudo, verifica-se que na região norte do estado de Mato Grosso, há maior ocorrência de dias chuvosos em relação região sul. Os autores, ao analisarem a distribuição e probabilidade de ocorrências de chuvas para a região de Cáceres em um período de 26 anos, encontraram média de dias secos e chuvosos de 305 e 60 dias respectivamente.

Nos resultados das médias mensais de dias secos e chuvosos (Figura 6), observa-se que os meses de dezembro, janeiro, fevereiro e março, foram os mais chuvosos com número de dias com precipitação superando os dias secos, com 17, 18, 16 e 17 dias de chuva respectivamente. No período de abril a novembro, o número de dias secos superou os dias com chuva, sendo junho, julho e agosto os mais críticos. 
- Dias Chuvosos $\square$ Dias Secos

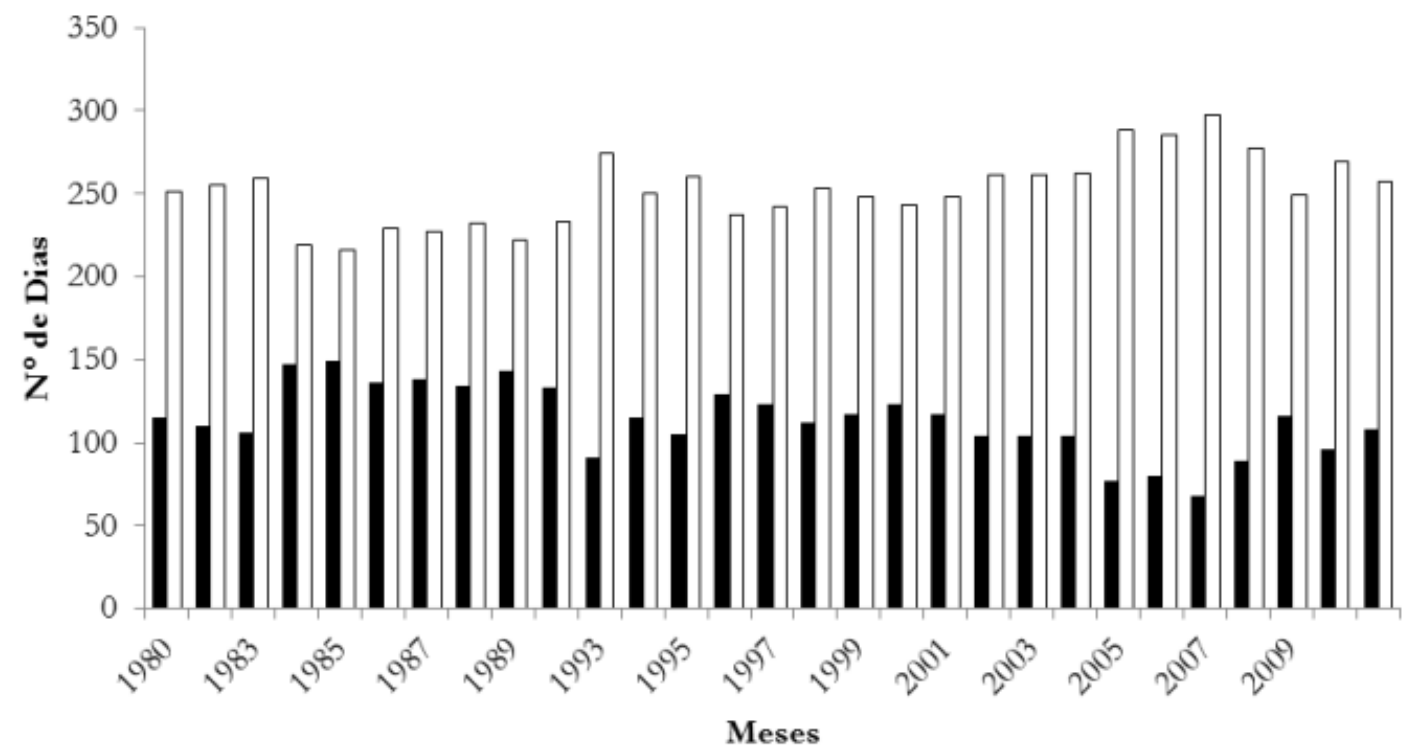

Figura 5. Ocorrência anual de dias secos e chuvosos no município de Juína - MT para o período de 1980 a 2011.

Moreira et al. (2010) analisaram a distribuição mensal de dias secos e chuvosos no período de 1983 a 2007 para a cidade de Nova Maringá - MT e concluíram a quantidade de dias secos foi superior ao de dias chuvosos, exceto nos meses de novembro e dezembro. No período de março a julho os dias chuvosos foram escassos, sendo caracterizado como a estação da seca no município.

\section{- Dias Chuvosos $\quad \square$ Dias Secos}

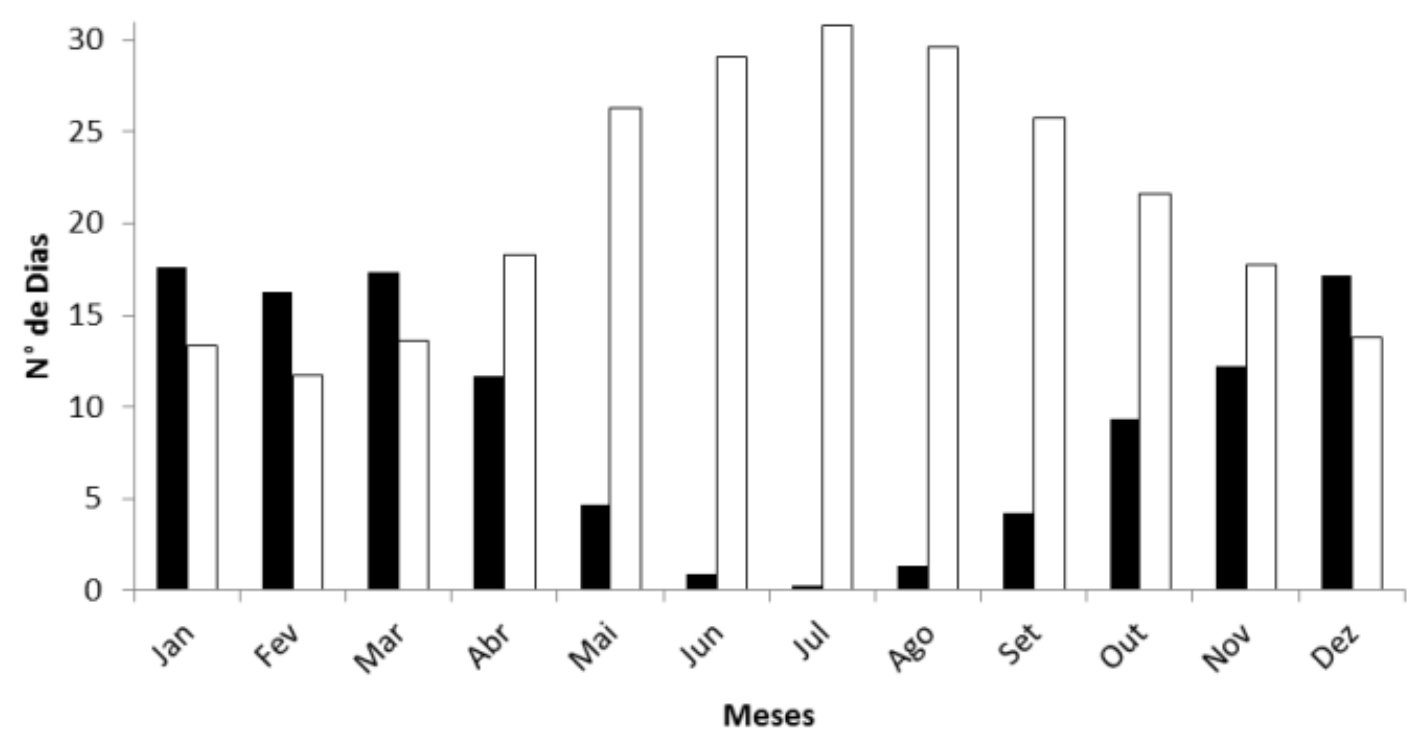

Figura 6. Média mensal de ocorrência de dias secos e chuvosos no município de Juína - MT para o período de 1980 a 2011. 
Correlacionando a média do índice pluviométrico com a média de dias chuvosos para os diferentes meses, verifica-se que o período de dezembro a março apresentou elevada intensidade pluviométrica, apresentando uma lâmina de precipitação diária superior a $20 \mathrm{~mm}$, caracterizando a ocorrência de chuvas intensas na região, com o mês de fevereiro apresentando maior intensidade de chuva de $27 \mathrm{~mm} \mathrm{dia}{ }^{-1}$. Almeida et al. (2012) afirma que chuvas individuais iguais ou superiores a $10,0 \mathrm{~mm}$ apresentam potencial erosivo. Neste aspecto, as chuvas nesse período são bastante erosivas, podendo ocasionar problemas de erosão do solo em áreas agrícolas.

Realizando a comparação da precipitação com o número de dias chuvosos para os diferentes anos, foi possível verificar que 1983, 2005, 2006, 2007 e 2010 apresentaram chuvas diárias mais intensas, com lâmina de precipitação acima de 20 $\mathrm{mm} \mathrm{dia}{ }^{-1}$, com o ano de 2005 apresentando o maior valor, com pluviosidade média diária de $27,4 \mathrm{~mm}$.

Ao analisar as médias mensais de precipitação pelo modelo de distribuição gama incompleta (Tabela 1) observou-se que o período de novembro a março apresentou $90 \%$ de probabilidade de ocorrência de chuvas com mais de $100 \mathrm{~mm}$, com os meses de janeiro e fevereiro caracterizando-se como os mais chuvosos do ano, com elevada probabilidade, mais que $90 \%$, de ocorrência de precipitação superior a 200 $\mathrm{mm}$, sendo que em ambos os meses, a probabilidade de ocorrência da média mensal aproximou-se de $50 \%$. Já os meses de junho e julho apresentaram uma baixa probabilidade de ocorrência de chuvas superiores a $10 \mathrm{~mm}$.

Durante este período com baixas precipitações recomenda-se manter a cobertura do solo, com vegetação ou palhada para manter a umidade e diminuir os riscos da estiagem sobre a produção agropecuária.

Em relação à distribuição anual da precipitação, observou-se que a média provável permaneceu entre 45 e $50 \%$ de ocorrência, com chuvas acima de 2.000 por ano apesentando níveis de probabilidade menores que $25 \%$.

É importante ressaltar que houve ajuste entre os índices pluviométricos reais e a probabilidade de ocorrência de chuvas, uma vez que os valores de $\beta$ não excederam a 100, tornando possível sua utilização. Para as estimativas das precipitações prováveis, quando valores de $\beta$ forem superiores a 100 , indicam que a distribuição Gama incompleta não pode ser utilizada (Thom 1958; Araújo et al., 2001). 
Tabela 1. Parâmetros alfa (a) e beta $(\beta)$ da distribuição gama para a precipitação pluviométrica mensal e níveis de probabilidade de ocorrência de chuva mensal e anual para o Município de Juína - MT.

\begin{tabular}{lccccccccc}
\hline \multirow{2}{*}{ Meses } & $\overline{\mathbf{Y}}$ & \multirow{2}{*}{$\mathbf{S}^{\mathbf{2}}$} & $\mathbf{a}$ & $\boldsymbol{\beta}$ & \multicolumn{5}{c}{ Probabilidade } \\
\cline { 7 - 10 } & & & & & $\mathbf{9 0 \%}$ & $\mathbf{7 0 \%}$ & $\mathbf{5 0 \%}$ & $\mathbf{3 0 \%}$ & $\mathbf{1 0 \%}$ \\
\hline Jan & 335,12 & 108,81 & 9,48 & 35,33 & 205,40 & 270,71 & 323,42 & 382,58 & 479,93 \\
Fev & 317,59 & 89,33 & 12,64 & 25,13 & 209,83 & 265,40 & 309,25 & 357,70 & 436,09 \\
Mar & 291,25 & 107,80 & 7,30 & 39,90 & 164,43 & 226,63 & 278,07 & 336,78 & 435,10 \\
Abr & 141,00 & 59,81 & 5,56 & 25,37 & 71,81 & 104,65 & 132,64 & 165,25 & 221,00 \\
Mai & 41,15 & 22,57 & 3,32 & 12,38 & 16,15 & 27,07 & 37,10 & 49,39 & 71,41 \\
Jun & 6,96 & 12,47 & 0,31 & 22,32 & 0,01 & 0,33 & 1,81 & 6,10 & 20,43 \\
Jul & 1,88 & 7,59 & 0,06 & 30,71 & 0,00 & 0,00 & 0,00 & 0,05 & 3,59 \\
Ago & 12,90 & 18,75 & 0,47 & 27,23 & 0,16 & 1,73 & 5,59 & 13,64 & 35,30 \\
Set & 52,96 & 36,99 & 2,05 & 25,84 & 14,41 & 29,37 & 44,64 & 64,56 & 102,41 \\
Out & 141,32 & 76,60 & 3,40 & 41,52 & 56,25 & 93,58 & 127,75 & 169,45 & 244,04 \\
Nov & 206,56 & 78,71 & 6,89 & 29,99 & 114,27 & 159,24 & 196,65 & 239,54 & 311,65 \\
Dez & 318,37 & 104,78 & 9,23 & 34,49 & 193,62 & 256,27 & 306,95 & 363,93 & 457,86 \\
\hline Total & 1867,05 & 251,14 & 55,27 & 33,78 & 1553,29 & 1727,64 & 1855,80 & 1990,15 & 2195,27 \\
\hline
\end{tabular}

\section{CONCLUSÃO}

A distribuição de chuvas na região de Juína (MT) apresentou uma variabilidade temporal anual de $2.507,5 ; 1.362,8$ e $1.867,05$ mm, para a máxima, mínima e média, respectivamente.

Com as médias decendiais observa-se um decréscimo de precipitação a partir do décimo decêndio até o vigésimo quinto decêndio.

A região apresenta duas estações definidas, uma estação seca de maio a setembro e outra chuvosa de outubro a abril.

A maior precipitação mensal ocorre em janeiro com média de 335,12 mm e a menor em julho com média de $1,88 \mathrm{~mm}$.

Os meses de dezembro, janeiro, fevereiro e março apresentam $90 \%$ de probabilidade de ocorrência de pluviosidade superior a $160 \mathrm{~mm}$.

\section{AGRADECIMENTOS}

Agradecemos a CAPES pelas bolsas concedidas aos mestrandos (André Lavezo, Alan Carlos Batistão e Marcos José Gomes Pessoa) e ao Programa de Pósgraduação em Biodiversidade e Agroecossistemas Amazônicos da Universidade do Estado de Mato Grosso, Campus de Alta Floresta - MT pelo apoio ao trabalho.

\section{REFERÊNCIAS BIBLIOGRÁFICAS}


ARAÚJO, W. F.; JÚNIOR, A. S. A.; MEDEIROS, R. D.; SAMPAIO, R. Precipitação pluviométrica mensal provável em Boa Vista, Estado de Roraima, Brasil. Revista Brasileira de Engenharia Agrícola e Ambiental, Campina Grande, v.5, n.3, p.563-567, 2001.

ALMEIDA, C. O. S.; AMORIM, R. S. S.; ELTZ, F. L. F.; COUTO, E. G.; JORDANI, S. A. Erosividade da chuva em municípios do Mato Grosso: distribuição sazonal e correlações com dados pluviométricos. Revista Brasileira de Engenharia Agrícola e Ambiental, vol. 16, n. 2, p. 142-152, 2012.

ASSAD, E. D.; SANO, E. E.; MASSUTOMO, E.; CASTRO, L. H. R de; SILVA, F. A. M da. Veranicos na região dos cerrados brasileiros, freqüência e probabilidade de ocorrência. Pesquisa Agropecuária Brasileira, Brasília, v. 28, n. 9, p. 993-1003, 1993.

ASSIS, F. N. Ajuste da função gama aos totais semanais de chuva de Pelotas - RS. Revista Brasileira Agrometeorologia, Santa Maria, v. 1, n. 1, p. 131-136, 1993.

BOTELHO, V.A.; MORAIS, A.R. Estimativas dos parâmetros de distribuição gama de dados pluviométricos do município de Lavras, Estado de Minas Gerais. Revista Ciência Agrotecnologia, Lavras, v. 23, n. 3, p. 697-706, 1999.

CATALUNHA, M. J.; SEDIYAMA, G. C.; LEAL, B. G.; SOARES, C. P. B.; RIBEIRO, A.. Aplicação de cinco funções densidade de probabilidade a series de precipitação pluvial no Estado de Minas Gerais. Revista Brasileira de Agrometeorologia, v. 10, n. 01, p. 153-162, 2002.

DALLACORT, R.; FREITAS, P. S. L.; FARIA, R. T.; GONÇALVES, A. C. A.; REZENDE, R.; BERTONHA, A.. Utilização do modelo Cropgro-soybean na determinação de melhores épocas de semeadura da cultura da soja, na região de Palotina, Estado do Paraná. Acta Scientiarum Agronomy. Maringá, v. 28, n. 4, p. 583-589, 2006.

DALLACORT, R.; MARTINS, J. A.; INOUE, M. H.; FREITAS, P. S. L DE; COLETTI, A. J. Distribuição das chuvas no município de Tangará da Serra, médio norte do Estado de Mato Grosso, Brasil. Acta Scientiarum Agronomy, Maringá, v. 33, n. 2, p. 193-200, 2011.

DOURADO NETO, D.; ASSIS, J. P.; TIMM, L. C.; MANFRON, P. A.; SPAROVEK, G.; MARTIN, T. N.. Ajustes de modelos de distribuição de probabilidade a séries históricas de precipitação pluvial diária em Piracicaba-SP. Revista Brasileira de Agrometeorologia, v.13, n.2, p.273-283, 2005.

FIETZ, C. R.; COMUNELLO, E.; CREMON, C.; DALLACORT, R. Probabilidade de Ocorrência de Períodos sem Chuva no Estado de Mato Grosso. Dourados: Embrapa Agropecuária Oeste, 2011, 95 p. (ISSN 1679-043X. Documento 113)

HIDROWEB: Sistema de Informações Hidrológicas. [Brasília, DF]: Agência Nacional de Águas, [2008]. Disponível em: <http: hidroweb.ana.gov.br>. Acesso em: 22 out. 2012.

IBGE. Instituto Brasileiro de Geografia e Estatística. Brasília, 2009.

MANCUZZO, F. F. N.; MELO, D. C. R.; COSTA, H. C. Sazonalidade e distribuição espaçotemporal das chuvas no bioma do cerrado do estado de Mato Grosso do Sul. Revista Brasileira de Recursos Hídricos, v. 17, n. 1, p. 77-86, jan-mar, 2012.

MANCUZZO, F. F. N.; MELO, D. C. R.; ROCHA, H. M. Distribuição espaço-temporal e sazonalidade das chuvas no estado do Mato Gross. Revista Brasileira de Recursos Hídricos, v. 16, n. 4, p. 157-167, out-dez, 2011. 
MARTIN, T. N.; DOURADO NETO, D.; VIEIRA JUNIOR, P. A.; MANFRON, P. A.. Homogeneidade espaço temporal e modelos de distribuição para a precipitação pluvial no estado de São Paulo. Revista Ceres, v.55, n.5, p.476-481, 2008.

MARTINS, J. A., DALLACORT, R, INOUE, M. R.; SANTI, A.; KOLLING, E. M.; COLETTI, A. J. Probabilidade de precipitação para a microrregião de tangará da serra, estado do Mato Grosso. Pesquisa Agropecuária Tropical, Goiânia, v. 40, n. 3, p. 291-296, jul-set, 2010.

MOREIRA. P. S. P.; DALLACORT. R.; MAGALHÃES, R. A.; INOUE, M. H.; STIELER, M. C.; SILVA, D. J da; MARTINS, J. A. Distribuição e probabilidade de ocorrência de chuvas no município de Nova Maringá-MT. Revista de Ciências Agro-Ambientais, Alta Floresta, v.8, n.1, p.9- 20, 2010.

PIZZATO, J. A.; DALLACORT, R.; TIEPPO, R. C.; MODOLO, A. J.; CREMON, C.; MOREIRA, P. S. P. Distribuição e probabilidade de ocorrência de precipitação em Cáceres (MT). Pesquisa Agropecuária Tropical, Goiânia, v. 42, n. 2, p. 137-142, abr-jun. 2012.

RIBEIRO, A.M.A.; LUNARDI, D.M.C. A precipitação mensal provável para Londrina-PR, através da função gama. Revista Energia Agricultura, Botucatu, v. 12, n. 4, p. 37-44, 1997.

ROSA, D. B.; SOUSA, R. R de; NASCIMENTO, L. A.; TOLEDO, L. G.; TOPANOTTI, D. Q.; NASCIMENTO, J. A do. A distribuição espacial das chuvas na porção centro-oeste do Estado de Mato Grosso - Brasil. Revista Eletrônica da Associação dos Geógrafos Brasileiros, Três Lagoas, v. 1, n. 5, p. 127-152, 2007.

SILVA, C.D. Determinação da precipitação pluviométrica provável par a cidade de BarreirasBA. Revista Energia Agricultura, Botucatu, v. 7, n. 1. p. 9-16, 1983.

SILVA, J. C.; HELDWEIN, A. B.; MARTINS, F. B.; TRENTIN, G.; GRIMM, E. L.. Análise de distribuição de chuva para Santa Maria, RS. Revista Brasileira de Engenharia Agrícola e Ambiental, Campina Grande, PB, v.11, n.1, p.67-72, 2007.

SOARES, A.A. Evapotranspiração de referência e precipitação provável no Estado de Minas Gerais visando a elaboração de projetos de irrigação. Revista Engenharia Agrícola, Jaboticabal, v. 18, n. 4, p. 14-18, 1999.

SOUSA, R. R.; ROSA, D. B.; NASCIMENTO, L. A.; LIMA, P. R. M. Estudo da variabilidade pluviométrica no extremo norte do Estado de Mato Grosso entre os anos de 1990 a 1996. Revista Geoambiente On-Line, Jataí, v.1, n.7, p.89-107, 2006.

SOUSA, R. R.; TOLEDO, R. G.; TOPANOTTI, D. Q. Oscilação das chuvas na porção centro oeste do estado de Mato Grosso, entre os anos de 1996 a 2001. Boletim Goiano de Geografia, Goiânia, v. 27, n. 3, p. 71-89, jun-dez, 2007.

SOUSA, S. A. V. Programa computacional para simulação da ocorrência de veranicos e queda de rendimento. Pesquisa Agropecuária Brasileira, v. 33, n. 12, p. 1952-1956, 1998.

THOM, H. C. S. A note on the gama distribution. Monthly Weather Review, Washington, v. 86, p.117-122, 1958. 